\title{
The Tromsø Heart Study: Serum selenium and risk of myocardial infarction a nested case-control study
}

\author{
JETMUND RINGSTAD, ${ }^{1}$ BJARNE K JACOBSEN, ${ }^{1}$ YNGVAR THOMASSEN, ${ }^{2}$ AND \\ DAG S THELLE ${ }^{1}$ \\ From the Institute of Community Medicine, ${ }^{1}$ University of Tromsø, Norway and the Institute of Occupational \\ Health, ${ }^{2}$ Oslo, Norway
}

SUMMARY The association between serum selenium concentration and the risk of myocardial infarction was studied in a nested case-control study. Altogether $59 \mathrm{men}$, initially free of disease, aged 28-54 at the time of blood sampling, died suddenly or experienced a fatal or non-fatal myocardial infarction during a six year follow-up period. Case-control pairs came from a population of 9364 persons examined in 1979-80 in the second Tromsø Heart Study. No significant difference was observed between serum selenium in cases and controls $(p=0.34)$. The major determinants of myocardial infarction and sudden death were raised levels of serum cholesterol and triglycerides $(\mathrm{p} \leq 0.001)$ and high systolic blood pressure $(\mathrm{p}<0.05)$. Thus, in this population with intermediate selenium intake, low serum selenium is not associated with an excess risk of myocardial infarction.

A number of reports suggest that the pathogenesis of cardiac ischaemic injury may be partly ascribed to the production of activated oxygen species.$^{1-3}$ Therefore, much interest has been focused on the trace element selenium, which is an essential prosthetic group for the enzyme glutathione peroxidase. ${ }^{4}$ This enzyme reduces lipid hydroperoxides (or hydrogen peroxide) to the corresponding lipid alcohols (or water), thereby possibly protecting the epithelium from oxidative damage. ${ }^{5}$ Glutathione peroxidase may also influence the synthesis of prostacyclin, an agent protective against platelet aggregation. ${ }^{6}$

The relationship between serum selenium concentration and the risk of ischaemic heart disease has not been convincingly proved. Between-area comparisons, ${ }^{7,8}$ case-control studies, ${ }^{9,10}$ and clinical observations $^{11}$ have produced some support for the role of selenium in coronary heart disease. Among the published prospective studies on selenium and the risk of death from ischaemic heart disease, one study found an inverse association, ${ }^{12}$ two studies were equivocal but suggested an inverse association among persons free of previous ischaemic heart disease, ${ }^{13,14}$ and in two studies no association was observed. ${ }^{15,16}$ These different findings have recently been discussed by Salonen. ${ }^{17}$

The present study was carried out to test the hypothesis that serum selenium is linked to the risk of myocardial infarction.

\section{Materials and methods}

For the present analysis we used data from the second Tromsø Heart Study in 1979-80, a population survey of cardiovascular risk factors. All men aged 20-54 and women 20-49, residents of Tromsø municipality (21 329 subjects), were invited; 16621 (78\%) participated. The examination comprised administration of a questionnaire identical with that used in the first Tromsø Heart Study ${ }^{18}$ and the cardiovascular studies in the Norwegian counties, ${ }^{19}$ measurement of blood pressure, height, and weight, and a collection of non-fasting blood samples for measurement of total serum cholesterol, HDL-cholesterol, triglycerides, and glucose. At the examination an extra blood sample was taken from the first 9364 subjects who attended the screening. These serum samples were frozen in closed plastic tubes at $-20^{\circ} \mathrm{C}$ for later analysis.

Persons who in the 1979-80 survey reported a history of myocardial infarction or chest pain previous to the examination were excluded from this study. During the subsequent six years (until 31 December 1985 ), 65 men, free of myocardial infarction or self-reported angina pectoris at screening, died suddenly of unknown cause $(n=8)$ or experienced a fatal or non-fatal myocardial infarction $(n=57)$. Nearly all sudden deaths of middle-aged men in Norway are due to coronary heart disease. ${ }^{20}$ No cases were found among the women. 
Data about acute myocardial infarction were obtained from the only hospital in the municipality, and data on deaths from myocardial infarction were derived from the Central Bureau of Statistics, Oslo, which registers all deaths in the country. There may, therefore, be non-fatal cases of myocardial infarction not registered in this study. Furthermore, only serum from 59 persons could be obtained, as serum samples from six myocardial infarction cases had been used for other non-selenium-related research purposes. One healthy control was matched pairwise to each of these cases according to sex, age (usually within the same year), daily consumption of cigarettes (non-smoker, $1-10,11-20,21-30,>30$ cigarettes per day), month of blood sampling, and place of residence (one of four parts of the municipality). One case was a pipesmoker. As no appropriate pipe-smoking control was available, he was matched with a man who smoked 1-10 cigarettes per day.

Both the cases and controls were free of present and previous cancer as assessed by crosslinking the information from the Cancer Registry of Norway.

The presented values for total cholesterol, HDLcholesterol, and blood pressure are the results from the 1979-80 survey of the Tromsø Heart Study. Total cholesterol was measured directly by the enzymatic oxidase method, using a commercial kit (Boehringer 148393). HDL-cholesterol was assayed by the same procedure after precipitation of lower density lipoproteins with heparin and manganese chloride. All of these laboratory assessments were performed shortly after the screening by the Division of Clinical Chemistry, University Teaching Hospital of Tromsø.

The selenium analyses were performed at the Institute of Occupational Health in Oslo in October 1986, when the serum samples were thawed for the first time. Selenium concentrations were determined by electrothermal atomic absorption spectroscopy after dilution with a nickel matrix modifier as proposed by Saeed et al. ${ }^{21}$ All analyses were done in duplicate and

in a random order, and calibration was done against standards based on human serum with a known content of selenium. ${ }^{21}$ Quality assurance of the selenium determinations was ensured using a certified reference serum as a quality control material. ${ }^{22}$ The coefficient of variation for the reference serum during one day was $2.8 \%$, and day-to-day variation based on the same serum sample was $5.9 \%$. The mean concentration (and standard deviation) of selenium in the reference serum for all days was $1.17(0.07) \mu \mathrm{mol} / \mathrm{l}$, while the proposed concentration is $1.15(0.08)$ $\mu \mathrm{mol} / \mathrm{l}^{23}$

Statistical analyses were performed with the Statistical Package for the Social Sciences (SPSS). ${ }^{24}$ The mean differences between cases and controls were tested for statistical significance with a T-test for paired samples.

\section{Results}

Table 1 shows the distribution of serum selenium concentration in cases and controls. The mean concentration of serum selenium (and standard deviation) was $1.57(0.21) \mu \mathrm{mol} / \mathrm{l}$ for all cases and 1.61 $(0.27) \mu \mathrm{mol} / 1$ for all controls. This difference $(0.04$ $\mu \mathrm{mol} / \mathrm{l})$ is not statistically different from zero $(\mathrm{p}=$ 0.34 ) (table 2). There were two particularly high values for serum selenium $(2.61$ and $2.68 \mu \mathrm{mol} / \mathrm{l})$, both in controls. If the two pairs with these controls were

Table 1 Distribution of serum selenium in cases and controls. The Tromsø Heart Study, 1979-80

\begin{tabular}{lcc}
\hline Serum selenium (umol/l) & Cases $(N)$ & Controls $(N)$ \\
\hline$\leq 1.29$ & 5 & 6 \\
$1.30-1.44$ & 9 & 7 \\
$1.45-1.59$ & 21 & 12 \\
$1.60-1.74$ & 13 & 22 \\
$1.75-1.90$ & 7 & 8 \\
$\geq 1.90$ & 4 & 4 \\
\hline
\end{tabular}

Table 2 Mean difference (and standard deviation) in serum selenium, number of cigarettes per day, age at examination, total cholesterol, HDL-cholesterol, triglycerides, blood pressure, and body mass index in 59 matched pairs of myocardial infarction cases and controls. The Tromso Heart Study, 1979-80

\begin{tabular}{|c|c|c|c|c|}
\hline & Cases & Controls & Difference & p-value \\
\hline Serum selenium ( $\mu \mathrm{mol} / \mathrm{l})$ & 1.57 & 1.61 & $0.04 \quad(0.35)$ & 0.34 \\
\hline Age at examination & 46.3 & 46.3 & $0.0 \quad(0.4)$ & 0.74 \\
\hline Cholesterol (mmol/l) & 7.55 & 6.50 & $1.05(1.78)$ & $<0.001$ \\
\hline HDL-cholesterol (mmol/l) & 1.41 & 1.51 & $0.10(0.78)$ & 0.33 \\
\hline Triglycerides $(\mathrm{mmol} / \mathrm{l})$ & 2.31 & 1.70 & $0.61 \quad(1.38)$ & 0.001 \\
\hline \multicolumn{5}{|l|}{ Blood pressure (mmHg) } \\
\hline Systolic & 141.2 & 134.7 & $6.5 \quad(24.2)$ & 0.04 \\
\hline Diastolic & 89.5 & 86.3 & 3.2 (16.5) & 0.14 \\
\hline Body mass index & 25.6 & 25.2 & $0.4 \quad(4.1)$ & 0.43 \\
\hline
\end{tabular}

- Matching variables 
excluded from the analyses, the mean serum selenium was 1.57 and $1.58 \mu \mathrm{mol} / 1$ in cases and controls, respectively. The selenium levels of the 21 fatal cases $(1.62 \mu \mathrm{mol} / \mathrm{l})$ were not significantly different from their controls $(1.56 \mu \mathrm{mol} / \mathrm{l})$.

We also tested whether low (in this study) serum selenium levels were associated with an increased risk of myocardial infarction. However, serum selenium levels below $1.45 \mu \mathrm{mol} / \mathrm{l}$ were not associated with a risk of myocardial infarction $(R R=1.0,95 \%$ $\mathrm{CI}=0.4-2.3$ ).

As cases and controls were matched on age and smoking, they had comparable means for age and number of cigarettes smoked daily (table 2). Of the 59 men 48 were daily smokers.

Table 2 shows the major cardiovascular risk factors in cases and controls. The differences between cases and controls were highly significant for cholesterol $(1.05 \mathrm{mmol} / \mathrm{l}, \mathrm{p}<0.001)$ and triglycerides $(0.61$ $\mathrm{mmol} / \mathrm{l}, \mathrm{p}=0.001$ ). Also systolic blood pressure was significantly higher in cases $(6.5 \mathrm{mmHg}, \mathrm{p}=0.04)$. HDL-cholesterol was lower in cases $(0.10 \mathrm{mmol} / \mathrm{l})$ but did not reach statistical significance.

Table 3 shows the distribution of serum selenium in cases and controls according to when the myocardial infarction occurred. The difference in serum selenium between cases and controls was not statistically significant in any period of follow-up. If the two above mentioned pairs are excluded from the analyses, the difference in serum selenium between cases and controls in all the three periods of follow-up was $\leq 0.01 \mu \mathrm{mol} / 1$.

\section{Discussion}

In this matched-pair, six-year follow-up study of men initially free of coronary heart disease, there were no differences in serum selenium concentration between cases and controls. The mean serum selenium values observed in this study are comparable with those in other Norwegian studies ${ }^{25,26}$ but are well above selenium levels in Finland (range 0.24-1.72 $\mu \mathrm{mol} / 1)^{13}$ where the other prospective studies have been conducted. ${ }^{12-15}$ Salonen et al have proposed that a

Table 3 Serum selenium (and standard deviation) ( $\mu \mathrm{mol} / \mathrm{l}$ ) related to when the myocardial infarction occurred. Months after blood sampling. The Tromso Heart Study, 1979-80

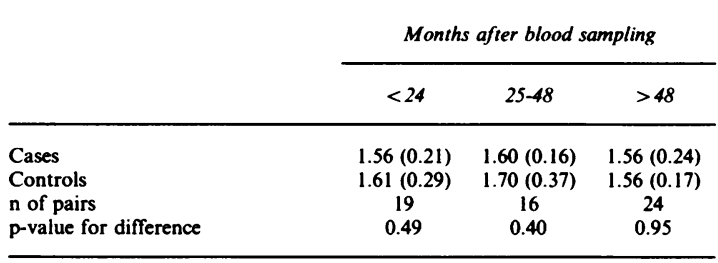

threshold value may exist in the relation of serum selenium to ischaemic heart disease. ${ }^{12}$ This may explain why no association was observed in this study with higher mean serum selenium levels.

We found higher serum cholesterol, triglycerides, and blood pressure in cases than in controls. One should note that these associations are univariate, and most studies have shown that the association between serum triglycerides and the risk of ischaemic heart disease disappears when adjusted for serum cholesterol. ${ }^{27}$ The difference in HDL-cholesterol between cases and controls in this study is significantly less $(p<0.05)$ than that found in the first Tromsø Heart Study. ${ }^{28}$ One possible reason for this is the matching for smoking habits.

A bias could be introduced as we do not have information about all cases of myocardial infarction in the six year follow-up of the population screened in the second Tromsø Heart Study. However, we do not find it likely that the serum selenium concentrations of cases not available to us (due either to no available serum sample or to non-fatal myocardial infarction after migration to other parts of the country) differ from the serum selenium concentrations of cases included in this study. The follow-up of men screened in the first Tromsø Heart Study in 1974 suggests that relatively few non-fatal events took place outside Tromsø, and only one out of 60 cancer cases was registered outside Tromsø in a similar follow-up study (unpublished observations).

It may be argued that serum selenium measured in one blood sample does not reflect the selenium status over years, and, even if there were an association between serum selenium and the risk of myocardial infarction, one should not expect to find any. However, the mean serum selenium in Finland and New Zealand with a recognised low food intake of selenium is lower than the serum selenium in, for example, Norway where a higher intake has been recorded. ${ }^{29}$ Furthermore, the repeated findings of a relation between low serum selenium and risk of myocardial infarction in Finland with a lower intake, suggests that serum selenium to some extent gives a valid picture of the intake.

Miettinen et al ${ }^{15}$ suggest that the relation between serum selenium below $0.57 \mu \mathrm{mol} / \mathrm{l}$ and risk of myocardial infarction in Finland is due to a coexisting low intake of selenium and eicosapentaenoic acid. In our population, with a rather high fish consumption, it is reasonable to believe that the intake of this nutrient is also adequate.

In summary, this study suggests that in populations with an intermediate selenium intake like the Norwegians, a low serum selenium level is not associated with an excess risk of myocardial infarction. Thus, in Norway, efforts should still be 
directed towards reducing blood lipids and blood pressure and discouraging smoking.

This study was supported by the Norwegian Research Council for Science and the Humanities and the Norwegian Council on Cardiovascular Diseases.

Correspondence and reprint requests to: $\mathrm{Dr} \mathrm{J}$ Ringstad, Institute of Community Medicine, University of Tromsø, Box 417, N-9001, Tromsø, Norway.

\section{References}

${ }^{1}$ Guarnieri C, Flamigni F, Caldarera CM. Role of oxygen in the cellular damage induced by re-oxygenation of hypoxic heart. J Mol Cell Cardiol 1980; 12: 797-808.

2 Shlafer M, Kane PF, Wiggins VY, Kirsh MM. Possible role for cytotoxic oxygen metabolites in the pathogenesis of cardiac ischemic injury. Circulation 1982; 66, suppl I:85-92.

${ }^{3}$ Thompson JA, Hess ML. The oxygen free radical system: A fundamental mechanism in the production of myocardial necrosis. Prog Cardiovasc Dis 1986; 28: 449-62.

${ }^{4}$ Rotruck J, Pope A, Ganther H, Swanson A, Hafeman D, Hoekstra W. Selenium: biochemical role as a component of glutathione peroxidase. Science 1973; 179: 588-90.

${ }^{5}$ Little C, O'Brien PJ. An intracellular GSH-peroxidase with a lipid peroxide substrate. Biochem Biophys Res Commun 1968; 31: 145-50.

${ }^{6}$ Schoene NW, Morris VC, Levander OA. Effects of selenium deficiency on aggregation and thromboxane formation in rat platelets. Fed Proc 1984; $43: 477$.

${ }^{7}$ Shamberger RJ, Gunsch MS, Willis CE, McCormack LJ. Selenium and heart disease. II. Selenium and other trace metal intakes and heart disease in 25 countries. In: Hemphill DD, ed. Trace substances in environmental health -XII. Columbia: University of Missouri Press, 1978: 48-52.

${ }^{8}$ Shamberger RJ, Willis CE, McCormack LJ. Selenium and heart disease. III. Blood selenium and heart mortality in 19 states. In: Hemphill DD, ed. Trace substances in environmental health -XIII. Columbia: University of Missouri Press, 1979: 59-63.

${ }^{9}$ Wang YX, Böcker $\mathrm{K}$, Reuter $\mathrm{H}$, et al. Selenium and myocardial infarction: glutathione peroxidase in platelets. Klin Wochenschr 1981; 59: 817-8.

${ }^{10}$ Oster O, Drexler M, Schenk J, et al. Serum selenium concentration of patients with acute myocardial infarction. Ann Clin Res 1986; 18: 36-42.

${ }^{11}$ Moore JA, Noiva R, Wells IC. Selenium concentrations in plasma of patients with arteriographically defined coronary atherosclerosis. Clin Chem 1984; 30: 171-3.
12 Salonen JT, Alfthan G, Huttunen JK, Pikkarainen J, Puska P. Association between cardiovascular death and myocardial infarction and serum selenium in a matchedpair longitudinal study, Lancet 1982; 2: 175-9.

13 Virtamo J, Valkeila E, Alfthan G, Punsar S, Huttunen JK, Karvonen MJ. Serum selenium and the risk of coronary heart disease and stroke. Am J Epidemiol 1985; 122 276-82.

${ }^{14}$ Salonen JT, Salonen R, Penttilä I, et al. Serum fatty acids, apolipoproteins, selenium and vitamin antioxidants and the risk of death from coronary artery disease. $\mathrm{Am} \mathrm{J}$ Cardiol 1985; 56: 226-31.

${ }^{15}$ Miettinen TA, Alfthan G, Huttunen JK, et al. Serum selenium concentration related to myocardial infarction and fatty acid content of serum lipids. $\mathrm{Br} \mathrm{Med} J$ 1983; 287: $517-9$

${ }^{16}$ Kok FJ, de Bruijn AM, Vermeeren R, et al. Serum selenium, vitamin antioxidants, and cardiovascular mortality: a 9-year follow-up study in the Netherlands. Am J Clin Nutr 1987; 45: 462-8.

${ }^{17}$ Salonen JT. Selenium in ischaemic heart disease. Int $J$ Epidemiol 1987; 16 (Suppl): 323-8.

18 Thelle DS, Førde OH, Try K, Lehmann EH, The Tromsø Heart Study: Methods and main results of the crosssectional study. Acta Med Scand 1976; 200: 107-18.

${ }^{19}$ Bjartveit K, Foss OP, Gjervig T, Lund-Larsen PG. The cardiovascular disease study in Norwegian counties. Acta Med Scand 1979; Suppl 634: 1-70.

${ }^{20}$ Westlund K. Myocardial infarction in Oslo 1967-69. Incidence and case fatality. J Oslo Cy Hosp 1972; 22 77-108.

${ }^{21}$ Saeed K, Thomassen Y, Langmyhr FJ. Direct electrothermal atomic absorption spectrometric $\bar{B}$ determination of selenium in serum. Anal Chim Acta 1979; 110: 285-9.

22 Ihnat M, Wolynetz MS, Thomassen Y, Verlinden M. Interlaboratory trial on the determination of total selenium in lyophilized human blood serum. Pure Appl Chem 1986; 58: 1063-76.

${ }^{23}$ Ihnat M, Thomassen Y, Wolynetz MS, Veillon C. Trace element data reliability in clinical chemistry Interlaboratory trials and reference materials. Acta Pharmacol Toxicol 1986; 59 Suppl VII: 566-72.

${ }^{24} \mathrm{Nie} \mathrm{NH}$, Hull CH, Jenkins JG. Statistical package for the social sciences. 2nd ed. New York: McGraw-Hill, 1975.

${ }^{25}$ Blekastad V, Jonsen J, Steinnes E, Helgeland K. Concentrations of trace elements in human blood serum from different places in Norway determined by neutron activation analysis. Acta Med Scand 1984; 216: 25-9.

${ }^{26}$ Aaseth J, Smith-Kielland A, Thomassen Y. Selenium, alcohol and liver diseases. Ann Clin Res 1986; 18: 43-7.

${ }^{27}$ Hulley SB, Rosenman RH, Bawol RD, Brand RJ. Epidemiology as a guide to clinical decisions. The association between triglyceride and coronary heart disease. N Engl J Med 1980; 302: 1383-9.

${ }^{28}$ Miller NE, Thelle DS, Førde OH, Mjøs OD. The Tromsø Heart Study: High-density lipoprotein and coronary heart-disease: A prospective case-control study. Lance 1977; 1: 965-8.

${ }^{29}$ Bibow K, Riis G, Salbu B. A study of trace elements in Norwegian diets by the duplicate portion technique. Näringsforskning 1984; 28: 84-8. 